\title{
Racismo, direitos e cidadania
}

\author{
LUÍSR. CARDOSO dE OLIVEIRA
}

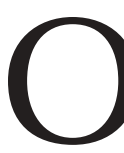

DEBATE ATU AL sobre a instituição de cotas para negros nas U niversidades enseja uma boa oportunidade para repensar a especificidade da discriminação racial no Brasil, e o potencial transformador das políticas de ação afirmativa propostas para combatê-la. Tendo como referência reflexões anteriores sobre a relação entre insulto moral e (des)respeito a direitos no Brasil, que tenho contrastado com situações similares nos EU A e no Q uebec (Cardoso de O liveira 2002), gostaria de explorar um pouco o que esta discussão tem a contribuir para a elucidação da discriminação racial entre nós. N esse empreendimento, vou procurar caracterizar brevemente o debate, para relacioná-lo em seguida com a questão mais ampla do respeito aos direitos de cidadania de uma maneira geral, trazendo à tona suas implicações para o cotidiano dos cidadãos, onde a articulação entre identidades, direitos e sentimentos ganha destaque. Finalmente, vou concluir o artigo com alguns comentários sobre o significado das cotas nesse quadro.

\section{R acismo e exclusão social à brasileira}

Pelo menos desde os anos de 1950, a Sociologia tem criticado a ideologia da democracia racial no Brasil, chamando a atenção para a incidência de discriminação no país, sem deixar de assinalar especificidades locais, particularmente acentuadas quando contrastadas com os EU A. N esse sentido, características como as do estilo indireto da discriminação, da vergonha do preconceito, e das ambiguidades da classificação racial têm sido comparadas à violência explícita da discriminação racial nos EU A, à existência do apartheid até os anos de 1960, e à nitidez da classificação racial, onde a chamada col or linepode ser estabelecida com precisão. A publicação do hoje clássico trabalho de 0 racy N ogueira - Preconcei to racial de marca e preconceito racial de origem (1954-1985) - foi um marco e se mantém como referência obrigatória para qualquer discussão sobre o tema, ainda que nem sempre ganhe a atenção devida. De qualquer forma, um desdobramento importante das contribuições deste perío do foi a consolidação da idéia de que se há, de fato, uma mistura entre raça e classe social na questão da discriminação, mas uma condição não explica a outra ${ }^{1}$. Em outras palavras, a ascensão social não elimina a discriminação racial, ainda que possa reduzi-la ou suavizá-la, assim como os pobres não deixam de estar mais sujeitos a atos de discriminação cívica do que os cidadãos de classe média, especialmente por parte da polícia (Kant de Lima, 1995), mesmo quando são classificados como brancos, se tomamos como referência a cor da pele². 
U ma das características das práticas de discriminação indireta vigentes no Brasil é que ela costuma aparecer de maneira dissimulada, sendo por vezes de difícil identificação mesmo para aqueles que sofrem na pele os seus efeitos. Além da discriminação ser uma prática ilegal, com penalidades previstas em lei, também é sancionada negativamente no plano moral, e não é de bom tom demonstrar preconceito. D esse modo, mesmo quando não se trata de esconder intencionalmente o preconceito, ele se manifesta freqüentemente de maneira irrefletida e a falta de consciência do ator sobre suas atitudes preconceituosas eventualmente esboçadas não é de todo surpreendente. A propósito, na abertura da pré-conferência sobre racismo e discriminação realizada em janeiro de 2001 na cidade de Porto Alegre, um representante da Fundação Palmares cita reportagem publicada na Fol ha de S. Paulo (edição de 14 de janeiro de 2001), sobre anúncio colocado no jornal por uma mulher de classe média alta à procura de uma empregada, assinalando que só aceitaria candidatas "brancas". I ndagada pela jornalista se os termos do anúncio não seriam uma indicação de racismo, a dona da casa argumenta que não, pois em sua família não há preconceito nem discriminação e enfatiza o fato de seu marido - um empresário - até recentemente ter tido pelo menos cinco empregados negros em sua empresa, os quais só teriam sido demitidos devido à crise econômica. Como indica o palestrante, é sintomático que, no momento de crise, os primeiros empregados demitidos tenham sido exatamente os negros. Exemplos de preconceito implícito ou irrefletido conjugados com práticas de discriminação racial indireta como esta são corriqueiros entre nós, e não permitem negar a existência de discriminação. Entretanto, eles revelam também a singularidade deste tipo de discriminação e suas implicações para a compreensão do problema no Brasil.

Além do caráter nebuloso do preconceito e da discriminação, estes não perdem a sua singularidade mesmo quando são assumidamente afirmados pelos atores. D e fato, não é novidade nem causa surpresa quando cor e classe social estão imbricados em manifestações de preconceito ou discriminação. Como por exemplo, no caso de mulheres negras que são impedidas de utilizar a entrada social de prédios na zona sul do Rio de J aneiro - como me foi relatado por duas negras norte-americanas que conheci nos EU A -, sob a al egação de que empregadas devem utilizar a entrada de serviço. É evidente que as duas mulheres foram classificadas como domésticas por serem negras.

Entretanto, o aspecto mais impressionante do racismo à brasileira está no fato de ele ser (radicalmente) relativizável ${ }^{3}$, ou de poder ser plenamente superado no caso de interações inter-raciais específicas, mesmo quando envolve atores com convicções racistas assumidas. A história de uma militante do movimento negro que conheci no evento de Porto Alegre ilustra bem este ponto. Filha de mãe branca e de pai negro, hoje separados, ela me disse que jamais entendeu 0 racismo de sua mãe, o qual, naturalmente, não impede que ela demonstre amor e carinho na relação com a filha ou com a neta, cujo fenótipo revela ascendência 
africana. Segundo a militante, sua mãe não esconde as convicções racistas que manifesta em seu cotidiano e, quando questionada pela filha sobre como teria sido capaz de casar com um homem negro, daria a seguinte resposta: - "Ah! seu pai é especial, é um homem inteligente, bonito, elegante, charmoso etc...." Em outras palavras, a mãe não poupava elogios quando falava do pai, que não teria qualquer um dos problemas ou características indesejáveis que ela costumava atribuir aos negros. A pesar da radicalidade e de uma certa excepcionalidade do exemplo, creio que ele revela um aspecto mais amplo e importante do racismo ou da discriminação cívica no Brasil. Em alguma medida, para a mãe racista da militante negra, o ex-marido representa uma versão incisiva e contundente da imagem do preto dealma branca, tão difundida entre nós. I sto é, a possibilidade de relativizar preconceitos a ponto de chegar a transformar uma relação inicialmente de antagonismo, com um interlocutor de identidade estigmatizada, numa relação de amor plenamente assumida. Tal situação não encontraria correlato nos EU A onde, ainda que o preconceito e a discriminação não inviabilizem relações sexuais interraciais entre pessoas racistas, seria impensável a transformação dessas relações em um casamento assumido.

Como tenho procurado argumentar ao contrastar as condições para o exercício da cidadania no Brasil e nos EU A, enquanto os estadunidenses enfatizam a importância do respeito aos direitos universal izáveis e impessoais do cidadão genérico, e orientam suas ações nessa direção, entre nós a classificação do interlocutor no plano moral teria precedência, fazendo com que o respeito a direitos fique, em grande medida, condicionado a manifestações de consi deração e deferência. O u seja, apenas aquelas pessoas nas quais conseguimos identificar a substância moral característica das pessoas dignas mereceriam reconhecimento pleno e (quase) automático dos direitos de cidadania. As idéias/ valores de respeito a direitose de consideração à pessoa corresponderiam, respectivamente, aos princípios de justiça e solidariedade no plano do exercício da cidadania, e qualquer desequilíbrio entre eles provocaria déficits de cidadania. Pois, em certas circunstâncias, não manifestar deferência ou consideração ao interlocutor pode ser vivido como uma agressão ou insulto e, portanto, como uma negação (desrespeito) de direitos, como minha análise de pequenas causas nos EU A indica e traz à luz uma fonte importante para os déficits de cidadania neste país (C ardoso de O liveira 1989; 1996; 2002; 2004).

A meu ver, essa precedência na vida cotidiana da noção de consideração à pessoa (singularizável) sobre a idéia de respeito aos direitos do indivíduo (genérico), assim como o caráter excessivamente seletivo da manifestação de consideração ao interlocutor, seriam os principais responsáveis pela incidência de discriminação cívica no Brasil, da qual a discriminação racial seria apenas a ponta do i ceberg (C ardoso de O liveira, 2002). N essa ótica, a discriminação racial seria um exemplo particularmente dramático e contundente de práticas de discriminação muito mais abrangentes, que se orientam pelo mesmo padrão ou atitude frente 
ao interlocutor portador de identidade estigmatizada ou que não permite, em princípio (ou em um primeiro momento), uma classificação favorável da identidade presumida. Em sua modalidade menos agressiva, a discriminação cívica apareceria de forma difusa, quando permitimos que um amigo tome a nossa frente na fila, por exemplo, sem nos preocuparmos com os que estão atrás de nós, os quais, apesar de não constituírem exatamente 0 alvo da discriminação, têm seus direitos desrespeitados. Contudo, a mesma atitude vai progressivamente ganhando contornos mais claros e definidos quando passamos da situação na qual fazemos nosso pedido falando mais alto ou de maneira mais incisiva no balcão do bar (farmácia, açougue etc.) sem atentar para os direitos daqueles que chegaram antes, até chegarmos em situações nas quais um interlocutor específico tem seus direitos abertamente desrespeitados, como nas abordagens policiais à população de baixa renda na periferia das cidades em que, literalmente, a polícia prende (ou bate) primeiro e depois pergunta. As cenas chocantes das atrocidades policiais flagradas por um cinegrafista amador em março de 1997 na Favela N aval em São Paulo ainda estão na nossa memória.

N essas circunstâncias, não é de se estranhar a importância atribuída aos documentos no Brasil, como instrumento de comprovação de uma identidade (singular) decente, de pessoa correta, merecedora de respeito e consideração. C omo assinala Kant de Lima, o D ecreto-L ei no 3.688, de 2 de outubro de 1941, definia "a vadiagem e a mendicância como contravenções penais" (1995, p. 55), fazendo com que a carteira de trabalho, além da carteira de identidade, tenha um significado estratégico para os mais pobres, sempre expostos à acusação de vadiagem. Santos já havia chamado a atenção para a relevância da carteira de trabalho como uma certidão de nascimento cívico, restrita aqueles trabal hadores cuja profissão/ ocupação estava regulamentada (1987, p. 69), assim como Peirano (1986, p. 2002) e D aM atta (2002, pp. 37-64) também tomam os documentos como símbolo de cidadania no Brasil. Em outras palavras, ainda que os direitos básicos de cidadania estejam constitucionalmente garantidos no Brasil, eles não são, de fato, acessíveis a contingentes expressivos da população na vida cotidiana. Aqui, não estou me referindo apenas àqueles aspectos das condições de vida da população carente em dissintonia com as garantias constitucionais (e.g., direito à moradia) devido às limitações orçamentárias do E stado, a políticas sociais ineficazes implementadas pelo governo, ou à crise econômica em sentido amplo, mas a atos de discriminação cívica que negam direitos em princípio acessíveis, agravando substancialmente as iniqüidades vigentes.

Por outro lado, assim como no caso da discriminação indireta contra os negros, a discriminação cívica contra os atores que têm sua dignidade negada no plano ético-moral pode ser revertida no momento em que a identidade desvalorizada é relativizada, e abrem-se perspectivas de (re)integração no plano da sociabilidade. D esse modo, tal quadro caracterizaria não só o racismo mas também a exclusão social à brasileira ${ }^{4}$. 


\section{D ireitos e sentimentos}

A pesar de preconceito e discriminação racial não serem exatamente a mesma coisa, são práticas freqüentemente associadas e poderiam ser concebidas como irmãs gêmeas do racismo. I sto é, se é planemante possível controlar o preconceito para evitar atos de discriminação, na medida em que é possível respeitarmos os direitos de um interlocutor com o qual não gostaríamos de estreitar vínculos ou conviver no plano da intimidade, a prática da discriminação indireta no Brasil revela não só a associação entre essas duas dimensões do racismo, mas demonstra também como uma dimensão pode ser acionada para esconder a outra, especialmente quando a aceitação do negro é apenas aparente e o preconceito disfarçado ou irrefletido conduz à negação de direitos. Como por exemplo, quando um profissional negro mais competente que seus concorrentes brancos é preterido na disputa pelo emprego, ainda que tenha motivos para achar que teve um bom rapport com seus entrevistadores no processo de seleção. N ão obstante, o padrão de relações raciais nos Estados U nidos seria um bom exemplo da possibilidade de tal controle se realizar, pelo menos naqueles aspectos em que a luta pelos direitos civis dos negros estadunidenses foi bem-sucedida. $\mathrm{N}$ a mesma direção, se, como indiquei acima, um dos problemas da universalização do respeito aos direitos de cidadania no Brasil estaria no filtro da consideração, através do qual não atentamos para os direitos daqueles que julgamos não merecedores de deferência na vida cotidiana, a bandeira do multiculturalismo nos EU A também demonstra que o respeito aos direitos do cidadão genérico não é suficiente para contemplar as demandas de cidadania dos negros estadunidenses, nem garante a integridade moral dos concernidos. A qui entramos na problemática da honra ou da dignidade, do reconhecimento ou da reciprocidade, e dos sentimentos.

Além das práticas de discriminação tradicionais, expressas por meio da negação direta e objetiva do acesso a direitos institucionalizados na sociedade em tela, e corriqueiramente exercidos pelos demais cidadãos, há um tipo de discriminação menos aparente, embora igualmente objetivo, o qual se expressa por meio do que tenho procurado caracterizar como insulto moral. Evidentemente, não me refiro aqui apenas aos insultos racistas acintosamente vocalizados por pessoas racistas, mas, principalmente, a situações e eventos nos quais a agressão ( racista) aos negros está embutida nos atos praticados, e não se traduz adequadamente em evidências materiais. I sto é, situações nas quais a observação aos direitos do interlocutor é acompanhada por um ar de desprezo ostensivo, ou simplesmente quando aquele que respeita os direitos não é capaz de transmitir, ao interlocutor, a convicção de que assim o faz porque reconhece sua dignidade ou a ad equação normativa dos respectivos direitos àquela circunstância. As demandas por reconhecimento da cultura ou da identidade afro-americana nos EU A referem-se não apenas à necessidade deste e de outros grupos minoritários serem valorizados, para que seus membros possam ter um desenvolvimento ou integração adequada na sociedade mais ampla, mas assinalam também como a falta de reco- 
nhecimento do valor ou mérito do grupo pode se constituir numa agressão. N os termos de nossa discussão, a falta de reconhecimento é percebida como um ato de desconsideração por meio do qual a identidade do grupo seria negada ou rejeitada, caracterizando uma atribuição de indignidade que não permitiria sua aceitação plena. É por isto que o (mero) respeito aos direitos civis dos negros, pelo menos parcialmente conquistado nos EU A, não é mais visto como condição suficiente para o exercício da cidadania, e reivindicações com foco exclusivo nos direitos civis perderam apelo ou se tornaram menos atraentes 5 .

Como tenho assinalado em relação à demanda por reconhecimento do Q uebec no âmbito do Canadá (C ardoso de O liveira 2002), uma das dificuldades para a satisfação das demandas por reconhecimento está no seu caráter radicalmente dialógico, que não pode ser contemplado exclusivamente no plano legal. O u seja, aquele que reconhece tem de ser capaz de demonstrar que assim o faz porque acha que deve fazê-lo e que o receptor do reconhecimento é merecedor desta deferência: reconhecer apenas por imposição legal pode ser, em si mesmo, um ato ofensivo. D este modo, o reconhecimento ou a consideração poderia ser definido como um direito moral ${ }^{6}$, de caráter eminentemente recíproco ( $C$ ardoso de O liveira, 2004), pois não pode se realizar unilateralmente ou na ausência de um mínimo de mutual idade entre as partes. $\mathrm{N}$ a mesma direção, o reconhecimento só se realiza adequadamente quando é produto da internalização de um sentimento. $\mathrm{N}$ ão no sentido psicológico do termo, tendo como referência as experiências íntimas de ego, mas em sua dimensão social, associado a experiências que só se dão em (ou na) relação, e de forma compartilhada. Tais experiências vêm à tona nas interações cuja realização demanda a produção de uma conexão entre as identidades de alter e ego, e estariam (quase) totalmente ausentes das interações que podem se desenvolver sem problemas no plano estritamente formal, onde reina a impessoalidade, e cujo sucesso não depende de quaisquer esforços de elaboração simbólica por parte dos atores. 0 tipo ideal dessas interações estritamente impessoais seria aquele em que interagimos, por exemplo, com o caixa do supermercado ou do banco, caracterizando situações cuja definição ou significado é socialmente cristalizado, sem espaço para negociação, e que sofrem um processo de dessimbolização em termos habermasianos ${ }^{7}$. 0 caso do caixa do banco ainda é mais radical, pois trata-se de situação na qual seres humanos têm sido sistematicamente substituídos por máquinas com sucesso, transformando uma relação social em uma relação literalmente instrumental, na qual o "interlocutor", prestador do serviço, objetivamente não tem voz ou ponto de vista.

Evidentemente, quando falo em discriminação e em (falta de) reconhecimento ou em (des)consideração e insulto moral tenho em mente relações que se encontram no pólo oposto ao da interação com o caixa eletrônico ${ }^{8}$. D a mesma forma, apesar de o preconceito contra negros e outros grupos sociais nem sempre se manifestar por meio de atitudes discriminatórias ou de insultos, é muito significativo o percentual de situações em que a mobilização do preconceito tem 
essa implicação, e mais significativo ainda o percentual de situações nas quais aquele que discrimina não tem consciência ou não está al erta para as conseqüências de seus atos no plano dos direitos. A ideologia da democracia racial e a vergonha do preconceito são alguns dos fatores que contribuem para isso, além da dificuldade mais geral, e muito mais abrangente, para internalizar a orientação normativa, de caráter universalista, que prega a igualdade de direitos e a não discriminação entre cidadãos, assim como estabelece a Constituição de 1988. Esse quadro levou-me a identificar uma desarticulação entre esfera pública e espaço público no Brasil, a qual, a meu ver, seria a principal responsável pela discriminação cívica entre nós (Cardoso de Oliveria, 2002, pp. 12 e 95-128). Pois, enquanto na esfera pública - tomada como "o universo discursivo onde normas, projetos e concepções de mundo são publicizadas e estão sujeitas ao debate público" à la H abermas (Cardoso de Almeida, 2002, p. 12) - há, hoje, uma clara hegemonia da idéia/ princípio da igualdade como um valor, no plano do espaço público - tomado como "o campo de relações situadas fora do contexto doméstico ou da intimidade onde as interações sociais efetivamente têm lugar" (Cardoso de Almeida, 2002, p. 12) - o filtro da consideração opera sistematicamente como eixo discriminador.

D e fato, em um país que após a abolição da escravatura nunca discriminou formalmente os negros, que estabeleceu leis anti-racismo há mais de cinqüenta anos, onde o Estado teve papel importante na divulgação da ideologia da democracia racial ${ }^{9}$, e no qual há grande interação sem tensão entre negros e bancos na vida cotidiana, não deveria ser difícil identificar esta dimensão da vida social como o locusprivilegiado onde, num só tempo, se manifesta e se esconde o racismo no Brasil. $\mathrm{N}$ ão é à toa que $\mathrm{H}$ élio Santos, uma liderança importante do movimento negro, assinala que "se deve considerar o cotidiano das relações raciais para se avançar significativamente neste tema" (Santos, 1997, p. 214). D o meu ponto de vista, esta dissintonia ou duplicidade entre integração plena e discriminação racial na vida cotidiana seria produto da desarticulação entre esfera e espaço públicos no Brasil, cuja superação demandaria esforços de rearticulação dessas duas dimensões da vida social.

\section{0 potencial transformador das "cotas" 10}

D iferentemente da maioria das propostas a favor das " cotas", que privilegiam a dimensão compensatória dessa medida no plano material, a ênfase de minha perspectiva está no potencial transformador da medida no plano simbólico, como instrumento de combate ao racismo. I sto é, em vez de acionar as "cotas" como política de inclusão social direta, dando acesso à renda através da entrada imediata na U niversidade, o objetivo precípuo da medida seria provocar uma mudança nas atitudes dos atores, para que se tornem mais críticos à discriminação e ao filtro da consideração. Estimulando assim maior preocupação com o respeito aos direitos de cidadania dos negros, e ampliando, indiretamente - mas de maneira 
mais efetiva - as oportunidades de participação do grupo na renda e na vida pública do país. A idéia seria de que o estabelecimento de um percentual mínimo de vagas para negros nas $U$ niversidades públicas faria com que a discriminação racial, e a sua inaceitabilidade numa sociedade democrática, fosse dramatizada periodicamente (quando da realização dos vestibulares), viabilizando a internalização do problema através da mobilização dos sentimentos dos atores em segmentos expressivos da sociedade e contribuindo, assim, para a rearticulação entre esfera e espaço públicos no Brasil, pelo menos no que concerne à crítica a nossas práticas cotidianas de discriminação cívica contra negros e cidadãos desprivilegiados de uma maneira geral. 0 fato de o vestibular caracterizar-se como um momento particularmente importante, e vivido com efer vecência não só pelos adolescentes que prestam o exame, mas também por suas famílias que compartilham com os candidatos as tensões e ansiedades deste híbrido de rito de passagem e competição moderna, onde nem todos são bem-sucedidos, coloca esse evento num patamar privilegiado para a dramatização do racismo e da discriminação como práticas inaceitáveis que demandam reparação. Faço agora alguns esclarecimentos sobre a proposta para concluir meu argumento sobre o potencial transformador e emancipatório das "cotas".

Em primeiro lugar, gostaria de dissociar a noção de "cota" aqui utilizada da idéia de proporção originalmente atribuída ao termo, assim como utilizado nos EU A, e que reflete uma relação de identidade entre o tamanho do grupo no âmbito da população de indivíduos ou cidadãos como um todo e a sua representatividade nas posições em que as "cotas" serão alocadas. N esse sentido, o percentual mínimo aqui proposto não guarda qualquer relação com a proporção ou representatividade do grupo na sociedade abrangente, e seu objetivo seria apenas provocar a percepção da discriminação como uma experiência compartiIhada no horizonte de todos e contra a qual todos devemos nos mo bilizar. Como se sabe, a dificuldade em estabelecer com precisão o percentual de negros (pretos e pardos) no Brasil tem sido apontada como um problema para a instituição das "cotas". Aliás, embora o foco da dificuldade esteja na definição da extensão da população de pardos e das alegações de manipulação que a auto-identificação permite, o problema não se resume a isso.

Para citar apenas um aspecto mal equacionado na literatura, gostaria de chamar a atenção para a precariedade dos dados relativos ao processo de branquemento da identidade associado à acensão social do ator, aparentemente muito acentuado na U niversidade. I sto é, há fortes indícios de que um percentual significativo daqueles que são computados como pardos e se idenficam como tais quando estão fora da $U$ niversidade têm sua identidade branqueada uma vez que estão lá dentro. Embora não tenha dados quantitativos sobre isso, descobri recentemente que vários colegas docentes na $U$ nB que nunca foram identificados como negros, nem jamais se situaram socialmente desta maneira, haviam sido classificados como pardos em suas carteiras de identidade. Da mesma maneira, é 
difícil distinguir dentre os inúmeros estudantes cujo fenótipo sugere ascendência afro-brasileira aqueles que se identificam como negros. 0 u seja, há também uma certa invisibilização da presença de negros (já!) na U niversidade, cujo significado demandaria novas pesquisas e melhor avaliação. $N$ ão estou sugerindo que não seja possível definir quem é negro no Brasil e teria direito às "cotas", nem que a possibilidade de manipulação seria uma ameaça significativa ao programa, argumento apenas que 0 estabelecimento de um percentual de vagas significativo no plano da compensação material seria sempre polêmico no que concerne à sua legitimação e poderia estimular reações contraproducentes em relação à discriminação e às perspectivas de integração.

Como demonstram as reações às cotas instituídas pela U ERJ no Rio de J aneiro, a dificuldade em legitimar o percentual de vagas e os procedimentos de distribuição, que tendem a estar mais sujeitos a questionamento e contestação conforme a abrangência do percentual atribuído às "cotas", pode provocar a racialização, a meu ver indesejada, das relações entre negros e brancos no país. Indesejada porque, na melhor das hipóteses, supondo que "cotas" amplas cumpram seu objetivo de promover maior equalização racial no plano material, a racial ização teria tudo para provocar tensão no plano da sociabilidade, e provavelmente ampliaria a discriminação asso ciada ao insulto moral ou ao (não) reconhecimento, conforme definido acima, ainda que consiga minorar ou mesmo eliminar a discriminação no acesso a direitos materiais, hoje sujeitos ao filtro da consideração. A propósito, como a discussão anterior sugere, a facticidade da integração horizontal no Brasil não significa grandes avanços em relação ao reconhecimento da identidade dos negros ou afro-descendentes, na medida em que, usualmente, os muitos exemplos de aceitação plena ou de manifestação de consideração a negros estão marcados pela relativização da identidade racial ou coletiva, não implicando a superação do estigma ou preconceito de forma mais ampla, para além da relação com um ator específico. Entretanto, dada a habilidade brasileira para contornar leis e a facilidade com que compartimentalizamos orientações normativas no plano dos princípios e orientações para a ação na vida cotidiana, nada garante que não serão encontrados mecanismos efetivos para contornar os "custos" e reduzir as vantagens dos beneficiados por "cotas" percebidas como excessivas. De todo modo, porque ampliar a integração vertical com prejuízos presumíveis para a integração horizontal, se podemos optar por caminhos que viabilizem a realização da primeira sem que tenhamos de abrir mão da segunda?

O estabelecimento de "cotas" equivalentes a um percentual mínimo de vagas no vestibular para todos os cursos das U niversidades públicas evitaria a grande maioria dos problemas geralmente atribuídos a esse tipo de política: a. não traria desvantagens reais para os não negros - inclusive os de baixa renda como a maioria dos negros - que continuariam tendo acesso à disputa da quase totalidade das vagas oferecidas no vestibular; b. to rnaria a discussão sobre a eventual manipulação da identidade dos beneficiados absolutamente irrelevante e fa- 
cilmente controlável pelo movimento social, sem necessidade de relativizar a autoidentificação como critério classificatório determinante; c. em vista da alta competitividade das vagas, que exclui sistematicamente um número substancial de candidatos com formação e competência plenamente suficientes para fazer os cursos, os questionamentos quanto ao mérito dos beneficiados também perde importância.

D a mesma forma, a crítica de que um número pequeno de vagas provocaria constrangimentos aos negros beneficiados pelas "cotas" e afetaria sua autoestima também parece-me pouco convincente pelas seguintes razões: a. nada indica que os beneficiados chamariam muita atenção na U niversidade que, de modo geral, está acostumada a conviver com a diversidade racial freqüentemente invisibilizada em vista do branqueamento da identidade acima aludido; b. pela mesma razão, mesmo nos cursos mais competitivos onde a presença de negros é menor a eventual ampliação de colegas negros não deve alterar muito a experiência dos beneficiados devido ao caráter do racismo à brasileira, que facilita a integração no plano da so ciabilidade; c. as U niversidades públicas já aceitam alunos por meios alternativos ao vestibular, sem qualquer ônus para estes, como por exemplo as transferências facultativas e convênios diversos com outros países que garantem matrícula para um certo número de alunos estrangeiros; $d$. independentemente do mecanismo de entrada na $U$ niversidade, nada é mais significativo para o mercado e a sociedade abrangente do que o desempenho acadêmico do aluno ao longo do curso, e a curta experiência com "cotas" no Brasil tem demonstrado que os estudantes beneficiados têm tido desempenho igual ou superior aos demais.

Q uanto ao potencial transformador das "cotas", através de sua atuação no plano simbólico, gostaria de tomar a sua distribuição periódica como característica do tipo de evento etnográfico que, como os rituais, seria portador de uma força performativa rica na produção de sentidos e na definição de relações sociais (Peirano, 2002). Dado o envolvimento da sociedade no acompanhamento do vestibular, a distribuição das "cotas" traria sempre à tona as razões de sua legitimação, permitindo que a existência e a inaceitabilidade do racismo fossem periodicamente lembradas não apenas em sua dimensão cognitiva, com distanciamento, mas também no plano dos sentimentos, ao tocar os atores através da experiência intensa e significativa daqueles que lhes são próximos. I sto é, dos vestibulandos. E mbora não creia que esta experiência de conexão entre princípios normativos e a vida cotidiana, contribuindo para a rearticulação entre esfera e espaço públicos no Brasil, venha a eliminar o preconceito racial entre nós, acredito que possa contribuir significativamente para o combate à discriminação cívica em geral, ao estimular a crítica à prática que associa preconceito à discriminação através do filtro da consideração. Se as "cotas" assim concebidas vierem a ter o mesmo sucesso das faixas de pedestre em Brasília, onde, ao produzir o gesto convencionado, os transeuntes não apenas param o trânsito para atravessar as ruas com seguran- 
ça, mas têm a cidadania renovada neste "rito" de afirmação e reconhecimento de direitos, a distribuição periódica das "cotas" poderá vir a ser concebida, num futuro próximo, como um rito de celebração da cidadania.

\section{N otas}

1 Edward Telles (2003) publicou recentemente uma avaliação abrangente da literatura articulada com a análise dos amplos dados quantitativos sobre o tema, demonstrando como as duas dimensões do problema estão presentes no "Racismo à brasileira". D esse modo, o racismo é estudado no plano das relações verticais (de classe) assim como no das relações horizontais (de sociabilidade).

2 A pesar de o fenótipo da pessoa ter precedência sobre o sangue, no racismo à brasileira, a classificação efetiva dos atores varia em função do contexto e de uma série de fatores, onde as idéias de cor e status se associam para marcar a interdependência entre contexto e classificação racial.

3 U m dos aspectos interessantes do livro de Telles (2003) é a demonstração com abundância de dados que, mesmo os números frios de gráficos e tabelas, têm que ser freqüentemente relativizados, conforme o contexto e a situação social de referência, para renovar o poder elucidativo dos mesmos.

$4 \mathrm{~N}$ esse sentido, a interação entre as dimensões vertical e horizontal das relações raciais - ou mesmo das relações sociais em sentido amplo - é bastante complexa, podendo, num só tempo, acentuar a exclusão no acesso a bens, serviços e oportunidades, assim como ampliar as possibilidades de integração e de mobilidade social.

5 Desse modo, não se ouve mais a idéia, vigente no movimento negro estadunidense nos anos de 1960, de que os negros não davam a mínima para o que os brancos pensassem sobre eles desde que seus direitos (civis) fossem respeitados.

$6 \mathrm{H}$ aroche e Vatin (1998) definem a consideração como um direito humano.

$7 \mathrm{O}$ s dois exemplos têm lugar naquelas áreas da sociedade moderna que $\mathrm{H}$ abermas caracteriza como estando sob o domínio dos steering media (dinheiro e poder) que gerem de forma semi-automatizada um universo significativo de relações na economia (mercado) e na política (H abermas, 1984 e 1987).

8 Certas situações ou interações sociais têm sua definição mais aberta à negociação do que outras, assim como a importância desta definição também varia de acordo com a experiência pregressa das partes e o contexto específico. Se dispusermos o universo de situações/ interações sociais em um contínuo, a interação com o caixa de banco estaria no pólo menos aberto à negociação. Entretanto, tal classificação não deve ser reificada e quase nenhuma situação/ interação estaria, a priori, totalmente imune à negociação ou a esforços de elaboração simbólica.

9 Só nos anos de 1990, ainda durante o primeiro mandato de Fernando $\mathrm{H}$ enrique Cardoso, um presidente da república admitiu que existe racismo no Brasil.

10 As "cotas" constituem apenas uma modalidade de ação afirmativa, e "cotas" na U niversidade apenas uma possibilidade de implementação destas. 0 s argumentos desenvolvidos aqui se referem exclusivamente a "cotas" na U niversidade. 


\section{Bibliografia}

CARD OSO DE OLIVEIRA, L. Fairnessand Communication in Small Claims Courts. (Ph.D dissertation, $\mathrm{H}$ arvard U niversity), Ann A rbor, U niversity M icrofilms I nternational (order \# 8923299), 1989.

. "D a moralidade à eticidade: via questões de legitimidade e eqüidade". Em R. L. R. Cardoso de O liveira. Ensai osantropológi cossobremoral eética. Rio de Janeiro, Tempo Brasileiro, 1996, pp. 105-142.

. Direito legal e insulto moral - Dilemas da cidadania no Brasil, Quebec e EUA. Rio de J aneiro, Relume D umará, 2001.

. "H onra, dignidade e reciprocidade". Série A ntropologia no 344. Braślia, U nB/ Departamento de Antropologia, 2004, pp. 2-16.

DA M ATTA, R. "A mão visível do Estado: notas sobre o significado cultural dos documentos". A nuário A ntropológico/99. Rio de J aneiro, Tempo Brasileiro, 2002, pp. 3764.

H ABERM AS, J. The Theory of Communicative A ction (vol. 1). Boston, Beacon Press, 1984.

The Theory of CommunicativeA ction (vol. 2). Boston, Beacon Press, 1985.

HAROCHE, C. e J-C. VATIN (orgs.). La Considération. Paris, Desclée de Brouwer, 1998.

KANT DE LIMA, R. A polícia da cidade do R io deJ aneiro: seusdilemase paradoxos 2a ed. rev. Rio de Janeiro, Forense, 1995.

NOGU EIRA, O. "Preconceito racial de marca e preconceito racial de origem". Em Tanto preto quanto branco: estudos de relações raciais. São Paulo, T.A. Q ueiroz, 19541985.

PEIRAN O, M. "Sem lenço e sem documento: reflexões sobre cidadania no Brasil". Em Estado e sociedade Brasília, ED U nB, vol. 1, no 1, 1986, pp. 49-64. 2002.

. 0 dito eofeito: ensai os deantropologia dosrituais. Rio de Janeiro, Relume D umará,

SANTOS, H. "D esafios para a construção da democracia no Brasil". Em SO UZA, J. (org.). M ulticulturalismo eracismo: uma comparação Brasil - EstadosU nidos. Brasília, Paralelo 15, 1997, pp. 209-219.

SANTOS, W.G. Cidadania ejustiça: a política social na ordem brasileira. 2a ed. rev. e atual. Rio de Janeiro, Campus, 1987.

TELLES, E. R acismoà brasileira: uma nova perspectiva sociológica. Rio de Janeiro, Relume D umará, 2003.

Resumo - o ARTIgo discute a singularidade do racismo no Brasil como um tipo de discriminação cívica articularmente importante mas que, não obstante, reflete um padrão muito mais abrangente de desrespeito a direitos e de agressão à cidadania. Tendo como foco práticas discriminatórias na vida cotidiana, que seriam estimuladas pela desarticulação 
entre esfera pública e espaço público no Brasil, o autor identifica o potencial das cotas no plano simbólico como instrumento de combate ao racismo e de afirmação da cidadania.

Abstract - the article discusses the singularity of Brazilian racism as a type of civic discrimination that is particularly important, but which, nevertheless, reflects a much broader pattern of disrespect for rights and aggressions to citizenship. Focusing on practices of discrimination in everyday life, which are stimulated by a disarticulation between the public sphere and public space in Brazil, the author identifies the potential of quotas at the symbolic level as a weapon against racism and as an assertion of citizenship.

LuísR. Cardoso de Oliveira é doutor em Antropologia pela U niversidade de $\mathrm{H}$ arvard e professor do D epartamento de Antropologia da U nB. Seu livro mais recente é $D$ ireito legal e insulto moral: dilemasda cidadania no Brasil, Quebec eEU A (R elume D umará).

Texto recebido e aceito para publicação em 26 de fevereiro de 2004. 